\title{
DAIRY SUPPLY CHAIN IN WEST JAVA: MODELLING USING AGENT-BASED SIMULATION AND REPORTING USING THE STRESS GUIDELINES
}

\section{Dr. Bhakti Stephan Onggo}

CORMSIS - Southampton Business School

University of Southampton, Southampton, UK

b.s.s.onggo@soton.ac.uk

\section{Dr. Dhanan Sarwo Utomo}

Centre for Sustainable Road Freight Heriot Watt University, Edinburgh, UK d.utomo@hw.ac.uk

\begin{abstract}
Agent-based simulation (ABS) is one of the preferred methods to model supply chains, especially when we are interested in estimating the impact of the interactions between individuals on system level outcomes. This paper presents a case study in which ABS is used to model the dairy supply chain in West Java. The characteristics of the supply chain in this case study, such as, the existence of forage as a common resource and the dominance of smallholder farmers, are different from most dairy supply chains in higher income countries. It is more common in low-middle income countries. ABS is used because we are interested in analysing the behaviour of the farmers, in particular, their buying and selling decision rules, and their impact on cow population and milk production. This paper demonstrates how the STRESS guidelines can be used to report the simulation study.
\end{abstract}

Keywords: Dairy Supply Chain, Agriculture, Agent-Based Simulation, Simulation Reporting Tool

\section{INTRODUCTION}

Like most dairy supply chains, a dairy supply chain in Indonesia is typically formed by many tiers comprising farmers (producers), cooperatives (collector and handler), milk processing industries (manufactures), retailers and consumers as shown in Figure 1. Most farmers are smallholders with low production levels. Our survey on 153 farmer households in 19 villages in the West Java shows that $98 \%$ of them are smallholders (own fewer than eight cows) and $85 \%$ of them own less than 600 $\mathrm{m}^{2}$ of land.

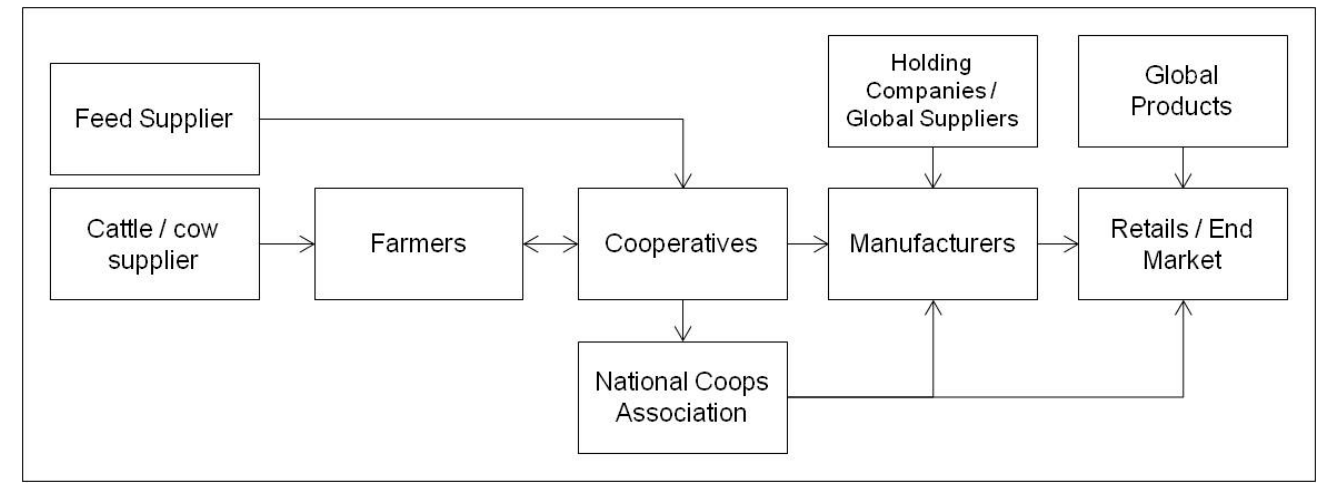

Figure 1 A typical dairy supply chain in Indonesia (Daud et al., 2015)

Milk is highly perishable so it must be transported efficiently and refrigerated at all times. This makes it prohibitively expensive for the smallholder farmers. Therefore, the role of a farmers' cooperative is important in transporting the milk from the farmers to the milk processors. It is also cheaper for the milk processing industries to buy milk in large quantities from cooperative than in 
smaller quantities from farmers. We are interested in designing policy interventions to help smallholder farmers and dairy supply chain in West Java. Hence, the first objective of our research is to model the dyadic interaction between smallholder farmers and the cooperative using agent-based simulation (ABS). ABS is chosen because it is arguably the best tool to model the interactions between agents (or decision making entities) and to estimate their impact on system level behaviours (Onggo, 2016; Macal, 2016).

This paper reports an ABS project using the STRESS (Strengthening the Reporting of Empirical Simulation Studies) guidelines (Monks et al. 2019, available online since 2018). Hence, the second objective of this paper is to demonstrate the application of STRESS guidelines to ABS reporting. Monks et al. (2019) introduced the STRESS guidelines to address the reproducibility issue in simulation studies (and simulation projects in general). The guidelines aim to improve how we report a simulation study and hence, it should lead to better reproducibility of simulation studies. The guidelines provide three checklists, STRESS-ABS, STRESS-DES and STRESS-SD, for agent-based simulation, discrete-event simulation and system dynamics, respectively. Since the guidelines is relatively new, the number of examples reported in the literature is limited. As far as we are aware, there is only one example that has been reported, i.e. Taylor et al. (2018). Hence, this motivates us to evaluate this new ABS reporting tool.

\section{DAIRY SUPPLY CHAIN IN WEST JAVA}

The dairy supply chain in the case study area (i.e. Pangalengan, West Java) is one of the biggest in Indonesia. We consider it representative of other dairy supply chains in the country. Hence, some of our findings can be generalized to other dairy supply chains in Indonesia.

The population density of Java island is high (approximately 1121 people $/ \mathrm{km}^{2}$ ) so the price of land is expensive. Hence, most farmers own relatively small area of land that is only sufficient to build a pen for their cattle. The pens are usually located next to the farmers' houses in the middle of residential areas (Figure 2, left). The farmers cannot herd their cattle through the residential areas as it may cause conflict with the residents. Therefore, they must gather forage from outside of their villages for their cattle. Depending on their wealth, they usually transport the forage using carts or motorcycles (Figure 2, right). The forage grows along the road and river banks. We can view the forage as a common resource for all these farmers. Consequently, when the forage availability is low (e.g. prolonged drought), the competition between farmers to obtain forage becomes more intense. The government is interested in cow population and volume of production. Hence, our model will be used to estimate these outputs.
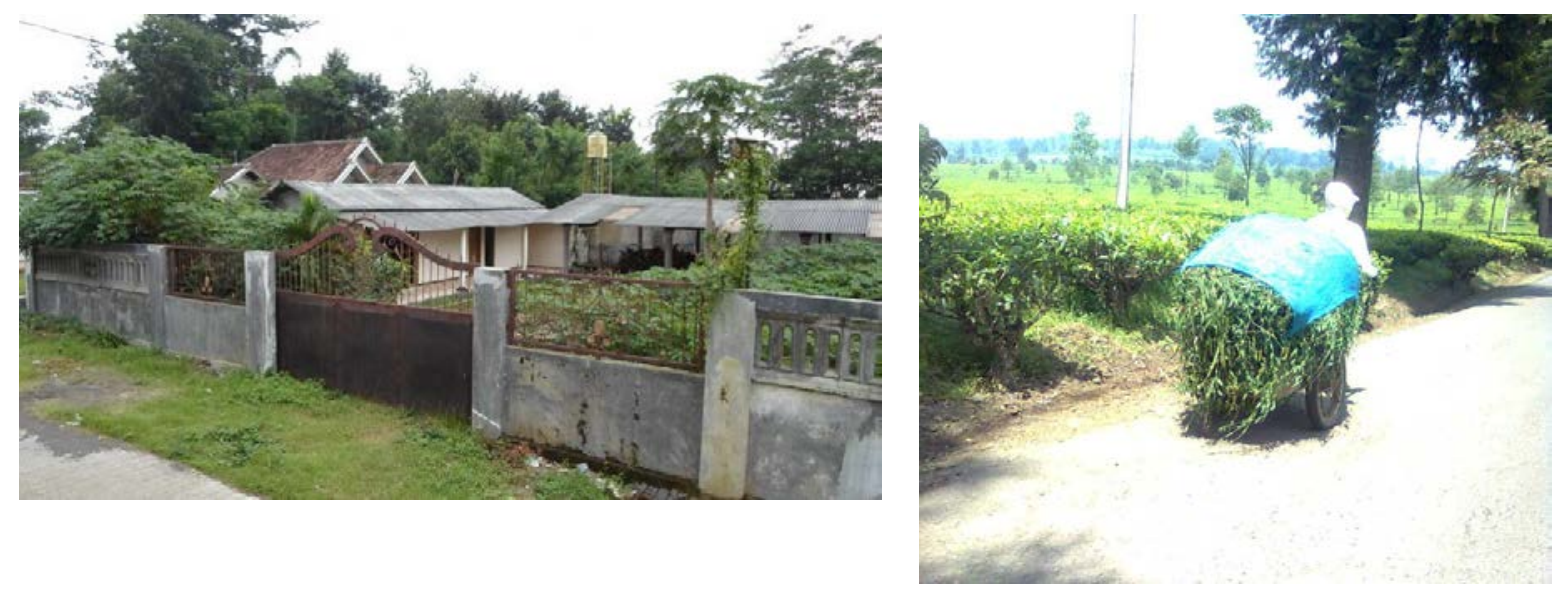

Figure 2 A cattle pen in the middle of a residential area (left). A farmer is transporting forage using a cart (right). 
Based on the World Bank definition, Utomo et al. (2018) reviewed research into agri-food supply chain and found that most research took place in high income (58\%) and middle income (37\%) countries. This economic development categorization is important because actors from different economic development levels may behave differently as shown in our case study. Hence, more research is needed to improve agri-food supply chains (including dairy) in low middle income countries (LMIC). This is important because most farmers in LMIC are smallholders and are more vulnerable to external events such as change in prices (supplies, competing imported products, retail) and extreme weather. At the same time, their role cannot be easily replaced by large farming companies for reasons such as employment, local economy and social stability. Foraging in farming is also an interesting field to study as it is also relevant to high income and middle income countries where resources are shared (e.g. fish in international waters or disputed maritime borders, water for irrigation system) and it may result in disputes or conflicts (e.g. the cod wars, the Nile river dam row).

\section{REPORTING THE MODEL USING STRESS GUIDELINES}

Although the details differ, the three checklists provided by the STRESS guidelines are organised into the same six sections: objectives, logic, data, experimentation, implementation and code access. In what follows, we describe our model and the experimentation using STRESS-ABS checklist. We develop the model in close collaboration with subject matter experts (lecturers and graduates from the Animal Husbandry Department at a local university and a farmer).

\subsection{Objectives}

This is where we explain the background and rationale for the model, the model outputs and questions to be answered using the model (Table 1). In ABS, we are typically interested in the system level outputs that that emerge from the interactions between agents. The outputs can be qualitative (e.g. patterns) or quantitative.

Table 1 Objectives

\begin{tabular}{lcl}
\hline Section/Subsection & Item & Recommendation \\
\hline $\begin{array}{l}\text { 1. Objectives } \\
\text { Purpose of the model }\end{array}$ & 1.1 & $\begin{array}{l}\text { The purpose of the model is to estimate the impacts of farmers' behaviours } \\
\text { on the dynamics of milk production, and cow population in West Java } \\
\text { Indonesia. }\end{array}$ \\
Model Outputs & 1.2 & $\begin{array}{l}\text { The outputs of the model are the daily milk production volume (in litres) and } \\
\text { the number of cows. }\end{array}$ \\
Experimentation Aims 1.3 & $\begin{array}{l}\text { The experimentation aim is to demonstrate how the hypothesized farmer's } \\
\text { buying and selling decision rules affect the daily milk production volume } \\
\text { and the number of cows. }\end{array}$ \\
\hline
\end{tabular}

\subsection{Logic}

In this section, we provide the model detail using suitable conceptual model representation (see Onggo 2010). If the experimentation involves scenarios that use multiple model, then we need to provide the detail for the models. In our case, we simply want to know the effect of the hypothesized buying and selling decision rules on model outputs. Hence, we do not compare scenarios.

Table 2 Logic

\begin{tabular}{lll}
\hline Section/Subsection & Item & Recommendation \\
\hline $\begin{array}{l}\text { 2. Logic } \\
\begin{array}{l}\text { Base model } \\
\text { overview diagram }\end{array}\end{array}$ & 2.1 & The main sequence of the simulation model is shown in the flowchart below. \\
\hline
\end{tabular}




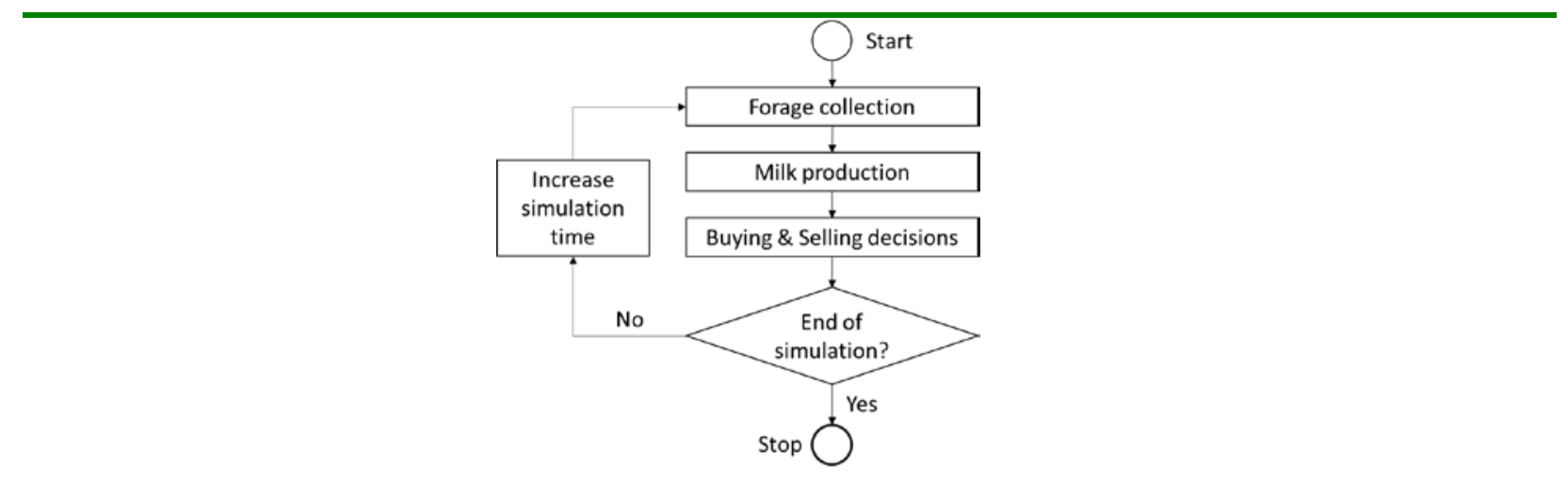

Farmers choose a reachable cell with the highest amount of forage and collect the forage (Martin et al 2016). The amount of forage collected is constrained by the capacity of the vehicles (cart, $40 \mathrm{~kg}$; motorcycle, $60 \mathrm{~kg}$; truck, $600 \mathrm{~kg}$ ) and time spent for collecting forage (source: expert opinion).

Milk production (source: expert opinion):

$Q m_{i}=$

$\left\{\right.$ MaxProd $_{i} *$ ProdEff $_{\left(\text {NumPreg }_{i}\right) * \overline{\text { Forage }}_{i}}$, ,PregPeriod $<7$ month

0 , PregPeriod $>7$ month

$Q m_{i}=$ the quantity of milk produced by cow $i$ in a day.

PregPeriod $=$ pregnancy duration

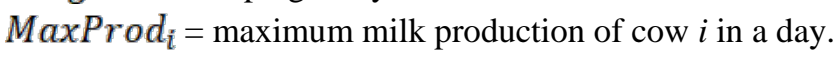

ProdEff = the production efficiency of cow $i$ which is a function of the number of pregnancies (NumPreg N $_{i}$. A cow achieves its maximum milk production after the second pregnancy $(\operatorname{ProdEff}(2)=100 \%)$ and the production efficiency then decreases linearly.

$\overline{\text { Forage }}_{i}=$ the average forage fulfilment of cow $i$ (between 0 and 1 , where 1 means that the given cow always obtains sufficient forage).

Buying decision (Gross et al. 2006):

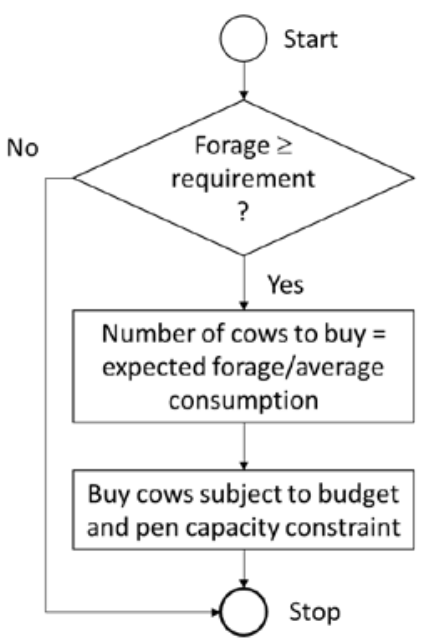


Selling decisions (Boone et al. 2011, Gross et al. 2016):
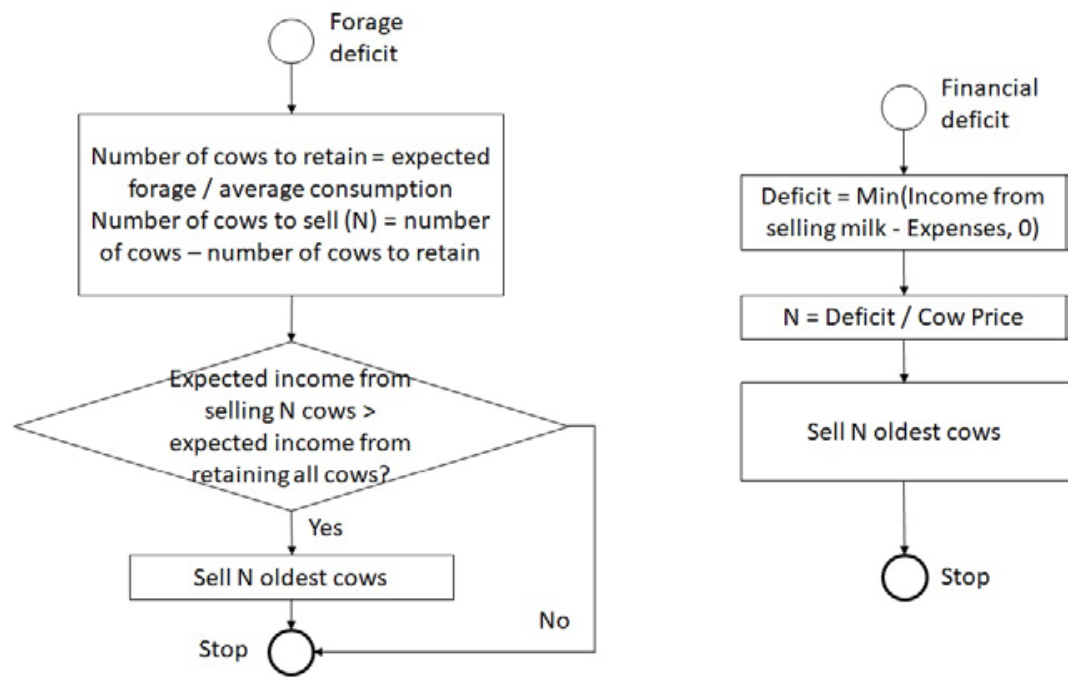

\begin{tabular}{lcl}
\hline Scenario Logic & 2.3 & Not applicable \\
\hline Algorithm & 2.4 & Not applicable \\
\hline Components & 2.5 & 2.5 .1 Environment
\end{tabular}

2D Grid containing 306 patches (each patch represents an area of one kilometre square). There are three types of patch:

- used patch: area occupied by building, houses, roads, etc

- unused patch: area that can be used to build new pens

- forage patch: area that are overgrown with forage

\subsubsection{Agents}

\section{Agent Patch}

Each time step, the amount of forage grows at rate (source: expert opinion and Bahar (2014)):

$$
\frac{d F}{d t}=\operatorname{Min}\left(\left(F_{\text {max }}-F_{t}-F c_{t}\right),\left(F_{t}-F c_{t}\right) *(1+G)\right)
$$

$F_{t}=$ initial forage level at day $t . F c_{t}=$ the amount of forage taken by the farmers on day $t . F_{\max }=$ the maximum amount of forage $(\mathrm{kg})$ per kilometre square (uniformly distributed between 270 and 734 tonnes per $\left.\mathrm{km}^{2}\right)$. $G=$ the forage growth rate $(1.1 \%$ per day).

\section{Agent farmer}

Forage collection, buying and selling decisions: see item 2.2

Note: cows are treated as agent farmer's property (not as an agent)

\section{Agent cooperative}

Cooperative will always buy milk from farmers and the price is a linear function of milk quality and, in turn, is a linear function of the amount of forage fed to the cows. 


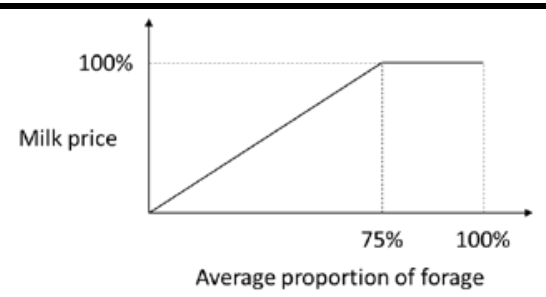

\subsubsection{Interaction Topology}

Agent farmers collect forage from agent patches

Agent farmers interact indirectly with each other via environment (i.e. forage)

Agent farmers sells milk to agent cooperative

\subsubsection{Entry / Exit}

No new agents are created. Agent farmer leaves when s/he has no money left or cow left.

\subsection{Data}

The principle of Garbage-In-Garbage-Out suggests that the quality of data determines the quality of the simulation outcome, especially in empirical simulation studies. Data collection has been identified as one of the main issues in simulation projects (Onggo and Hill 2014) and modellers spend up to $40 \%$ of their project time dealing with data issues (Onggo et al. 2013). Hence, it is important to document the data and the data collection process.

Table 3 Data

\begin{tabular}{|c|c|c|}
\hline Section/Subsection & Item & Recommendation \\
\hline $\begin{array}{l}\text { 3. } \quad \text { Data } \\
\text { Data sources }\end{array}$ & 3.1 & $\begin{array}{l}\text { Secondary data from BPS (2017), KBPS (2016), expert opinion } \\
\text { Primary data from: } \\
\text { - Interview with the stakeholders and expert was done to face validate the } \\
\text { base model and to pilot test the survey instrument, } \\
\text { - Close-ended and scenario-based questionnaire survey. The respondents } \\
\text { are } 153 \text { farmer households in } 19 \text { villages in West Java. The data was } \\
\text { collected in August } 2016 \text {. }\end{array}$ \\
\hline Pre-processing & 3.2 & $\begin{array}{l}\text { Standard descriptive statistics and distribution fitting; The questionnaire } \\
\text { used traditional measurement units. Therefore, we needed to convert them } \\
\text { into international units. }\end{array}$ \\
\hline Input parameters & 3.3 & $\begin{array}{l}\text { Number of farmers, proportion of patches (item 2.5.1), run length, farmers' } \\
\text { characteristics (e.g. age, number of cows), farmers' retirement age, prices } \\
\text { (e.g. calf, cows, milk). The details are as follows: } \\
\text { - } \quad \text { Farmer agents' age in years: Triangular ( } 22,74,38) \\
\text { - } \quad \text { The number of family labour per households: Binomial (0.92) } \\
\text { - } \quad \text { Number of cows own by each household (heads): Poisson (4.1) } \\
\text { - } \quad \text { Number of bulls own by each household (heads): Poisson (0.81) } \\
\text { - } \quad \text { The peak milk production of a cow (litre/day): Normal (20.81, 19.35) } \\
\text { - } \quad \text { Service per conception a cow (times): Poisson ( }(2.38) \\
\text { - } \quad \text { Average cow selling price (millions IDR/head): } 13.1 \\
\text { - } \quad \text { Average bull selling price (millions IDR/head): } 16.4 \\
\text { - } \quad \text { Average heifer buying price (millions IDR/head): } 9.6\end{array}$ \\
\hline
\end{tabular}


- $\quad$ Minimum milk price (IDR/litre): 3350

- $\quad$ Maximum milk price (IDR/litre): 5200

- Additional fodder price (IDR/Kg): 2400

$\begin{array}{lll}\text { Assumptions } & 3.4 & \text { Farmers' home are spread randomly across the grid, retirement age is the }\end{array}$ same for all farmers, farmers work maximum of eight hours per day.

\subsection{Experimentation}

The settings in which the model is used to generate outputs are described in this section. This includes the warm up period for the non-terminating simulation, initial system state condition, run length and estimation approach (e.g. replications, batch means).

Table 4 Experimentation

\begin{tabular}{|c|c|c|}
\hline Section/Subsection & Item & Recommendation \\
\hline 4. Experimentation & & \\
\hline Initialisation & 4.1 & $\begin{array}{l}\text { Most input parameters (item 3.3) are set using the user interface (Figure 3); } \\
\text { farmers' characteristics are sampled using the distributions obtained based } \\
\text { on the primary and secondary data (item 3.1). }\end{array}$ \\
\hline Run length & 4.2 & 5 years \\
\hline Estimation approach & 4.3 & The model is stochastic. Each scenario uses 25 simulation replications. \\
\hline
\end{tabular}

\subsection{Implementation}

This section provides information about the execution platform which is important due to the lack of backward compatibility in some software tools. This information is essential if the performance measures such as computation speed and memory requirement are needed (e.g. when we propose a faster algorithm than the existing one).

Table 5 Implementation

\begin{tabular}{lcl}
\hline Section/Subsection & Item & Recommendation \\
\hline $\begin{array}{l}\text { 5. Implementation } \\
\text { Software or } \\
\text { programming language }\end{array}$ & 5.1 & NetLogo 5 \\
$\begin{array}{l}\text { Random sampling } \\
\text { Model execution }\end{array}$ & 5.2 & $\begin{array}{l}\text { Built-in functions from NetLogo } \\
\text { ABS model is using fixed time steps. NetLogo randomise the sequence of } \\
\text { agents activation in each step to avoid bias. }\end{array}$ \\
System Specification & 5.4 & Not relevant, i.e. we do not measure computation speed \\
\hline
\end{tabular}

\subsection{Code access}

Open Science initiative aims to make research accessible to wider audience, especially publicly funded research. Taylor et al. (2017) discuss how Open Science principles applicable to simulation. In ABS community, the formation of CoMSES network (https://www.comses.net/) with the OpenABM platform is aligned with the Open Science principles. Hence, we expect that more simulation models will be accessible. Our code is not ready for public access at the time of writing. When it is ready, we will upload it to the OpenABM platform. 


\subsection{Simulation Results}

The model is implemented using NetLogo (Wilensky 1999). The user interface is shown in Figure 3. The farmers are shown in red circles. The cooperative is shown in yellow square. The three patches, i.e. used, unused and forage, are shown in black, brown and green, respectively. Darker shades of green indicate higher amount of forage.

The simulation outputs, i.e. number of cows and daily milk production, are shown in Figure 4. Qualitatively, the simulation outputs (black lines) show the same downward trend observed in the real-world (dark grey lines). Quantitatively, the simulation outputs do not perform well as shown that the real-word data fall outside the 95\% prediction intervals (shown in the dotted grey lines). For our purpose, since we are more interested in the medium-term planning (once every five years), the ability to reproduce the patterns is sufficient. This model would allow us to demonstrate the qualitative impact of interventions (such as subsidy) that can change farmers' behaviours on milk production and number of cows. However, if we want to use the model for short-term planning in which the accuracy of the estimates are important, we need to collect more data at the individual level. Indeed, further research (Utomo 2018) shows that the behaviours of farmers in West Java are different from the hypothesized behaviours used in the base model.

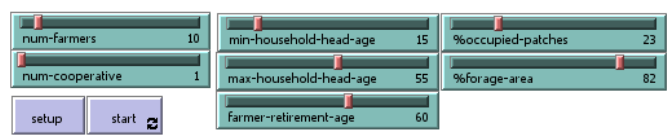

\section{Concentrate Factors}

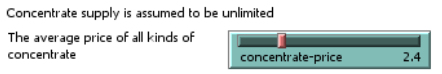

Milk Price

The buying price of milk with the
highest quality set by the cooperative

The buying price of milk with the
lowest quality set by the cooperative

The milk price received by
cooperative from milk process

Livestock Price Factors

Male / female calf price

The cow price when it is culled
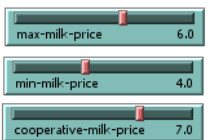

Cooperative Decisions

Handling policy (indivudual grading

Cooperative produce and sell
complete feed

The daily prodcution if the The dally prodcution if the
cooperative choose to produce
complete feed

The profit margin when selling

Cooperative's policy to buy selected
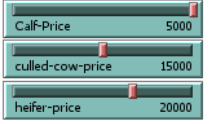

hereer from farmers

The cost to feed and rear
cooperative's cows. The fodder

quantity ys sassumed to be external
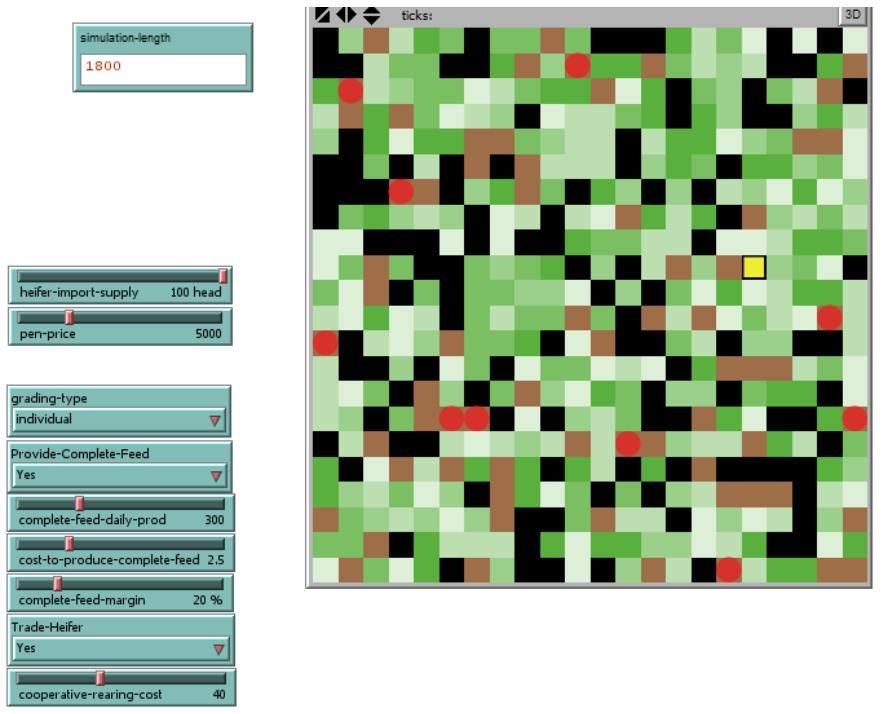

Figure 3 Model user interface in NetLogo
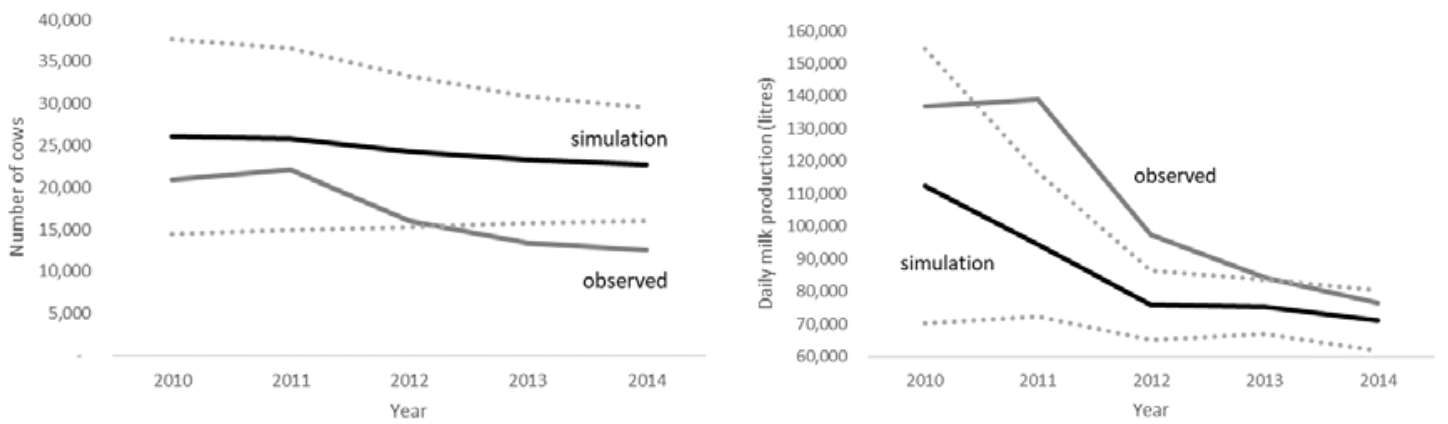

Figure 4 Cow population (left) and daily milk production (right)

This kind of ABS model is useful when we want to evaluate policy or intervention to change farmers' behaviours. The reason is that we can simulate the impact of a target behavior in comparison 
to an existing behaviour on certain system level performance. The quantification of the estimated impact can complement a behavioural operations experiment which aims to find an effective intervention that can change existing behaviours.

\subsection{Personal reflection on STRESS guidelines}

Upon reflection, the fact that the STRESS guidelines are deliberately not prescriptive is useful. It makes the guidelines easier to use since we can concentrate on the check lists instead of how to write or format the document. The drawback of not being prescriptive is that we need to decide the right scope and level of detail that should be written in the document. The document should help us understand the computer simulation model or code but it should not explain all functions or variables. Hence, we still have to judge the scope (e.g. which functions and variables to include) and level of detail (e.g. block diagram, flow chart or detailed pseudocode). A too detailed report takes a lot of time to produce and may hinder the clarity of the report by focusing on the unnecessary details. There are details that are better documented in the computer model or code.

Related to the above is the issue of confidentiality. Detailed models such as the production lines in a factory can be confidential. Hence, it is not always practical to produce the report. However, we argue that it may be even more important to document such a model because the model is likely to be a high value asset. The issue of confidentiality can be mitigated by using a good security system that manages access to the report.

Another advantage is that the guidelines provides us with the list of most likely items that a reader needs to reproduce a simulation model and experiments using the model. This should help us minimise the number of missing important information.

\section{CONCLUSION}

This paper has applied STRESS guidelines to report a simulation study of a dairy supply chain in West Java. The case study shows that a dairy supply chain in LMIC may have different characteristics in comparison to dairy supply chain in high income countries, for example, the majority of farmers are smallholders and the presence of foraging behaviour. Hence, more research is needed to understand and improve the supply chain in LMIC. We have also implemented an ABS model to estimate the effect of farmers' behaviours on cow population and milk production. This model can be useful in estimating the impact of behavioural changes on population level performance such as milk production.

On reflection, the fact that the STRESS guidelines are deliberately not prescriptive is useful but at the same time, we need to decide the right scope and level of detail. The guidelines are especially useful in providing a list of commonly required information to understand a model. Like similar initiatives, as the guidelines become widely used and tested, we will know more about what needs to be improved.

\section{REFERENCES}

Bahar S (2014). Produktivitas hijauan pakan untuk produksi sapi potong di Sulawesi Selatan. JITV, 19. Available: https://docplayer.info/47163408-Produktivitas-hijauan-pakan-untuk-produksi-sapipotong-di-sulawesi-selatan.html [Acessed 23 August 2019]

Boone R, Galvin K, Burnsilver S, Thornton P, Ojima D and Jawson J (2011). Using coupled simulation models to link pastoral decision making and ecosystem services. Ecology and Society, 16.

BPS (2017). Agricultural and Animal Husbandry Census [Online]. Available: https://www.bps.go.id/subject/24/peternakan.html\#subjekViewTab3 [Accessed 22 December 2017]

Daud A, Putro U and Basri M (2015). Risks in milk supply chain: A preliminary analysis on smallholder dairy production. Livestock Research for Rural Development, 27:137. 
Gross J E, McAllister R R J, Abel N, Smith D M S and Maru Y (2006). Australian rangelands as complex adaptive systems: A conceptual model and preliminary results. Environmental Modelling \& Software, 21:1264-1272.

KPBS 2016. Data Populasi dan Penghasilan Anggota KPBS. Unpublished Dataset.

Macal C M (2016). Everything you need to know about agent-based modelling and simulation. Journal of Simulation, 10(2): 144-156.

Martin R, Linstädter A, Frank K \& Müller B (2016). Livelihood security in face of drought Assessing the vulnerability of pastoral households. Environmental Modelling \& Software, 75:414423.

Monks T, Currie C, Onggo B S S, Robinson S, Kunc M, and Taylor S J E (2019). Strengthening The Reporting of Empirical Simulation Studies: Introducing the STRESS Guidelines. Journal of Simulation, 13(1): 55-67.

Onggo B S S (2010). Methods for Conceptual Model Representation. In Robinson S, Brooks R, Kotiadis K. and van der Zee D-J (eds). Conceptual Modelling for Discrete-Event Simulation. Taylor and Francis: Boca Raton, FL, pp 337-354.

Onggo B S S, Hill J, and Brooks R J (2013). A Pilot Survey on Data Identification and Collection in Simulation Projects. In: Proceedings of the 27th European Simulation and Modeling, Onggo B S S and Kavicka A (eds). Eurosis-ETI: Ostend, Belgium, pp 77-84.

Onggo B S S and Hill J (2014). Data Identification and Data Collection Methods in Simulation: A Case Study at ORH Ltd. Journal of Simulation 8(3):195-205.

Onggo B S S (2016). An introduction to agent-based simulation as a decision-support tool. In: Anagnostou A, Hoad K and Kunc M (eds). Proceedings of the 8th Operation Research Society Simulation Workshop. The Operational Research Society: Birmingham, UK, pp 1-12.

Taylor S J E, Anagnostou A, Fabiyi A, Currie C, Monks T, Barbera R, and Becker B (2017). Open Science: Approaches and Benefits for Modeling \& Simulation. In Proceedings of the 2017 Winter Simulation Conference, Chan W.K.V. et al. (eds). IEEE: Piscataway, New Jersey, 535-549.

Taylor S J E, Anagnostou A, Monks T, Currie C, Onggo B S S, Kunc M and Robinson S L (2018). Applying the stress guidelines for reproducibility in modeling \& simulation: Application to a disease modeling case study. In Proceedings of the Winter Simulation Conference. IEEE: Piscataway, New Jersey, pp 739-748.

Utomo D S, Onggo B S S, Eldridge S (2018). Applications of Agent-Based Simulation in the AgriFood Supply Chains. European Journal of Operational Research, 269(3): 794-805

Utomo D S (2018). Improving and Comparing Data Collection Methodologies for Decision Rule Calibration in Agent Based Simulation. A Case Study of Dairy Supply Chain in Indonesia. PhD thesis. Department of Management Science, Lancaster University.

Wilensky U (1999). NetLogo: Center for Connected Learning Computer-Based Modeling. Northwestern University: Evanston, IL.

\section{AUTHOR BIOGRAPHIES}

BHAKTI STEPHAN ONGGO is an Associate Professor of Business Analytics at Southampton Business School, the University of Southampton. He is a member of the Centre of Operational Research, Management Sciences and Information Systems (CORMSIS). His research interests lie in the areas of simulation modelling methodology (symbiotic simulation, hybrid modelling, agent-based simulation, discrete-event simulation) with applications in operations and supply chain management as well as health and social care. He is the Associate Editor for the Journal of Simulation. His email address is b.s.s.onggo@soton.ac.uk. His website is https://bsonggo.wordpress.com

DHANAN SARWO UTOMO is a Research Associate in Centre for Sustainable Road Freight, Heriot-Watt University. He received his MS degree from Institut Teknologi Bandung, and earned his $\mathrm{PhD}$ from Lancaster University. His research interests are in computer simulation and modelling areas i.e., system dynamics and agent-based simulation. He is also interested in the application of computer simulation and modelling e.g., in agriculture, public sector, environment, and logistics. His email address is d.utomo@hw.ac.uk. 